\title{
Psychosocial job characteristics and psychological distress / well-being: the mediating role of personal goal facilitation
}

\author{
Renato Pisanti ${ }^{1}$, Margot van der DoeF ${ }^{2}, \mathrm{Stan}_{\mathrm{MAES}}^{2}$, Cristiano Violani ${ }^{3}$ and \\ David LAZZARI ${ }^{4}$
}

${ }^{1}$ Niccolò Cusano University, Faculty of Psychology, Italy, ${ }^{2}$ Leiden University, Institute of Psychology. Clinical, Health and Neuropsychology Unit, The Netherlands, ${ }^{3}$ Sapienza University of Rome, Department of Psychology, Italy and ${ }^{4}$ Hospital S. Maria, Section of Clinical and Medical Psychology, Italy

\begin{abstract}
Psychosocial job characteristics and psychological distress / well-being: the mediating role of personal goal facilitation: Renato PISANTI, et al. Niccolò Cusano University, Faculty of Psychology, Italy-Objective: This study examined the mediating role of personal goal facilitation through work (PGFW), defined as perceptions of the extent to which one's job facilitates the attainment of one's personal goals, in the association between psychosocial job characteristics and psychological distress and jobrelated well-being. Material and Methods: Questionnaire data from 217 nurses ( $84 \%$ female, with a mean age of 42.7 years, $S D=7.2$ ) were analyzed. Participants completed the following measures: the Leiden Quality of Work Questionnaire for Nurses, Workplace Goal Facilitation Inventory, Maslach Burnout InventoryHuman Services Survey, and Utrecht Work Engagement Scale (short version). A cross-sectional study design was applied. Hierarchical multiple regression analyses were conducted. Results: The results indicated that unfavorable psychosocial job characteristics (high demands, low control, and low social support) were associated with lower PGFW. Furthermore, personal goal facilitation through work explained significant additional variance (from 2 to $11 \%$ ) in psychological distress (somatic complaints and emotional exhaustion) and job-related well-being (personal accomplishment, job satisfaction, and work engagement), controlling for demographic indicators and psychosocial job characteristics. Finally, the results provided support for the mediating effects of PGFW between all psychosocial job characteristics and all outcomes, except in the case of depersonalization. Conclusions: This study suggests that hindered personal goal facilitation may be a mechanism through which psychosocial job char-
\end{abstract}

Received Apr 23, 2015; Accepted Sept 9, 2015

Published online in J-STAGE Oct 31, 2015

Correspondence to: R. Pisanti, "Niccolò Cusano" University,

Faculty of Psychology, Via Don Carlo Gnocchi, 300166 Rome, Italy (e-mail:Renato.Pisanti@unicusano.it) acteristics have a negative impact on employees' wellbeing.

(J Occup Health 2016; 58: 36-46)

Key words: Burnout, Nurses, Personal goal facilitation through work, Psychosocial job dimensions, Work engagement

Research conducted in the health-care sector in several countries suggests that nursing work has become increasingly stressful, with levels of psychological distress exceeding those of general population norms ${ }^{1)}$. In the last few years, a state of emergency within nursing professionals has been evident in Italy in terms of high turnover, high rates of retirement, and contemporary low recruitment, so the Italian health-care context is characterized by one of the lowest ratios of nurses per capita (6.0 active nurses per 1,000 people) in Europe ${ }^{2)}$.

Psychosocial job characteristics and personal goal facilitation

It is widely recognized that certain psychosocial job characteristics may contribute to employee psychological distress and well-being. The three most studied psychosocial job dimensions in relation to mental health are job demands, job control, and social support from colleagues and supervisors ${ }^{3)}$. These variables form the core components of the Job Demands-Control-Social Support (JDCS) model ${ }^{3)}$, and as suggested by Kompier and Taris ${ }^{4}$, they have been identified as critical job features in a variety of theoretical approaches such as the demand-induced strain compensation (DISC) model $^{5)}$ and the job demands resources model ${ }^{6}$. Psychosocial job demands relate to work load and refer to the dimensions of the job environment that might overburden employees' personal capacities, such as time pressure, role conflict, and quantitative workload. Job control, or decision lati- 
tude, refers to a person's ability to control his or her work activities and includes aspects such as skill utilization, task control, and decision authority. The third dimension, social support, was added to the model later, and it refers to instrumental and emotional support from colleagues and superiors ${ }^{3)}$.

Pomaki and $\mathrm{Maes}^{7}$ related the three JDCS variables to basic human needs. According to selfdetermination theory ${ }^{8}$, subjects strive to fulfill three basic needs: competence, autonomy, and relatedness. These needs link to the JDCS variables: demands with competence, control with autonomy, and social support with relatedness ${ }^{7}$. However, how the psychosocial job variables are related to need constructs and how the perception of unfavorable psychosocial job conditions can interfere with the fulfillment of these basic needs are still scarcely investigated ${ }^{7}$. More specifically, more research is needed on how contextual factors are related to intrinsic motivation ${ }^{9)}$. As indicated, many occupational stress models assume that occupational demands (stressors) and job resources, such as job control and social support, underlie strain and wellbeing. Among them, the Job Demands-Resources (JDR) model can be considered an extension of the JDCS model, and it argues that two general categories (i.e., job demands and job resources) are associated with job strain and well-being ${ }^{6)}$. The model assumes that job demands are physical, psychosocial, and organizational job dimensions that involve physical or psychological efforts and are therefore associated with certain physiological and psychological costs. Job resources are defined as physical, psychosocial, and organizational dimensions that permit an individual to achieve work goals and deal with job demands and the associated physiological and psychological costs and/or that stimulate personal growth and development. Several studies suggest that self-regulation theory could add a complementary point of view to these occupational stress models ${ }^{7,11,12)}$. Self-regulation theory argues that most human behavior is goal directed and that singular behaviors are thus organized or directed by personal goals. Goals are "internal representations of desired states, where states are broadly construed as outcomes, events, or processes" (p. 338) $)^{13)}$. In the self-regulation literature, authors agree on the fact that individuals pursue multiple goals simultaneously. From an occupational health psychology perspective, a sizeable amount of research has focused on the process of goal pursuit ${ }^{14)}$. The perception that one is progressing towards or attaining valued goals is considered by several authors an important determinant of satisfaction and well-being ${ }^{14)}$. Goals serve as an important reference for the cognitive and affective system, so people experience positive feelings when they make progress toward goals and negative feelings when they fail to reach their goals. Progressing towards goals, perceiving that they have been achieved, anticipating success, and perceiving clarity and little difficulty may facilitate well-being. In a previous review ${ }^{15}$, the researchers found that goal progress was associated with improved affect. Moreover, some studies ${ }^{16)}$ in the literature have shown that the perception of attainability of goals accounts for interindividual differences in emotional well-being and satisfaction with life. Engaging in some goaldirected behaviors may be helpful and increase the likelihood that a particular goal-directed behavior will be performed, thereby representing goal facilitation. Several studies conducted in the work and health psychology areas have shown that the perception of goal facilitation may affect both intention to perform a health-related behavior and its subsequent performance directly and indirectly ${ }^{16,17)}$.

In the area of occupational health psychology, personal goal facilitation through work (PGFW) refers to perceptions of the extent to which one's job facilitates the attainment of one's personal goals ${ }^{12}$. In a cross-sectional study conducted among 1,036 healthcare workers, personal goal facilitation through work accounted for significant variance in well-being and distress variables, even after controlling for JDCS dimensions. More specifically, all regression coefficients observed for the four goal facilitation scales (personal growth goals, physical well-being goals, social relationship goals, and self-confidence goals) were positively related to favorable job attitudes (job satisfaction and personal accomplishment). Furthermore, two of the goal facilitation scalesrepresenting respectively work's facilitation of selfconfidence goals and physical well-being goalswere negatively associated with psychological distress measures (emotional exhaustion and somatic complaints). These findings indicated that personal goal facilitation through work explained unique variance in well-being/distress outcomes beyond the impact of psychosocial job variables ${ }^{12)}$. However, it has also been suggested ${ }^{7)}$ that personal goal facilitation is likely to mediate the influence of psychosocial job variables and distress outcomes. More specifically, the notion is that deleterious psychosocial job conditions (high job demands, low job control, and social support) can predict psychological well-being via direct effects and indirectly by hindering the opportunities for employees to pursue their valued goals. In addition, favorable job conditions can have a direct beneficial impact on well-being as well as an indirect one by facilitating the attainment of personal goals. To our knowledge, there are no studies that have explored the mediating role of employees' perceptions of progressing towards or attaining 
valued personal goals through work in the relationship between psychosocial job variables and distress/wellbeing outcomes.

Thus, in order to examine the ideas discussed above, the main aim of the present study was to analyze whether PGFW mediates the effect of JDCS variables on employee psychological distress and wellbeing. In order to examine employee psychological distress/well-being comprehensively ${ }^{18)}$, outcome variables from several distress/well-being dimensions were included in the present cross-sectional study, namely indicators of context-free psychological distress such as somatic complaints (psychosomatic dimension) and indicators of domain-specific distress/well-being, such as burnout (affective, social, and professional functioning dimensions), job satisfaction (affective dimension) and job engagement (cognitive dimension). Somatic complaints involve symptoms caused by the perception of bodily dysfunction, such as headache and back pain. We considered somatic health complaints because previous studies ${ }^{19)}$ showed that, among nurses, somatic complaints levels are above the average risk level. Burnout can be defined as a psychological syndrome of emotional exhaustion, depersonalization, and reduced personal accomplishment that may occur in response to chronic (especially interpersonal) stressors on the job ${ }^{20)}$. It has been estimated ${ }^{21)}$ that professional burnout could affect $25 \%$ of nurses, but this percentage can rise to $64 \%$ in nurses who work in wards characterized by high affective strain ${ }^{21)}$. Job satisfaction can be defined as "a positive (or negative) evaluative judgment one makes about one's job or job situation"22). Previous studies ${ }^{23}$ identified it as a key factor in nurses' recruitment and retention. Finally, we considered job engagement because previous studies showed that engagement could mediate the impact of nursing work environments on patient safety outcomes $^{24)}$. Job engagement is defined as a positive, fulfilling, work-related state of mind that is characterized by vigor, dedication, and absorption ${ }^{25)}$.

\section{Objective}

Three hypotheses are addressed in this study. The first hypothesis deals with the associations between psychosocial job variables and PGFW. We hypothesized that, after controlling for the effects of background variables such as age and gender, low scores for job demands and high scores for job control and social support would be associated with high scores for PGFW (hypothesis 1).

Further, we expected that high levels of PGFW would be associated with lower scores for the three dimensions of psychological distress (somatic complaints, emotional exhaustion, and depersonalization) and higher scores for the three job-related psychological well-being variables (personal accomplishment, job satisfaction, and work engagement) above and beyond the JDCS variables (hypothesis 2).

Finally, the third hypothesis dealt with the mediation role of PGFW. We expected that the psychosocial job variables and psychological distress/well-being outcomes would be indirectly associated via PGFW (hypothesis 3).

\section{Materials and Methods}

\section{Sample and procedure}

The study was conducted between September 2011 and March 2012 at a public university hospital, S. Maria hospital (Terni-Umbria region). Power calculations were conducted to establish an appropriate sample size. Based on achieving a small effect size, as observed in other similar studies ${ }^{17}$, with a statistical power of .80 and inclusion of up to 20 predictor variables (including demographics) into the planned final regression model, we aimed to recruit a minimum of 210 participants ${ }^{26)}$.

At the time of the survey, 404 nurses were employed at the hospital. The eligible population $(\mathrm{N}=351)$ consisted of all nurses who had patient contact. Moreover, head nurses and nursing managers were excluded from the sample. The investigators approached subjects during workshops of the in-service training curriculum. Sixty-four subjects did not attend the courses for several reasons (e.g., they were not interested, or they were not available). For privacy reasons, personal data of this group were not available. Two hundred and eighty-seven nurses were approached regarding participation. Before data were collected by means of paper and pencil questionnaires, the researchers provided information about the purpose and design of the study. Two hundred and seventeen questionnaires (response rate: 76\%) were returned. Of the respondents, the majority were female $(84 \%)$. The mean age was 42.7 years $(\mathrm{SD}=7.2$; range $=28-56$ ), and $36 \%, 28 \%$, and $26 \%$ worked in emergency wards, surgical wards, and medical wards, respectively. On average, respondents had been working in a health-care setting for 17.0 years $(\mathrm{SD}=9.1$; range $=1-37$ years). More than $62 \%$ of the nurses had a bachelor's degree, and almost $74 \%$ of the nurses worked full time (38 h/week) $67.3 \%$ worked rotating shifts, including night shifts. Participants and nonparticipants did not differ in terms of age and gender. The voluntary nature of the study was emphasized. In Italy, ethical approval from the ethics committee of participating hospitals is required, and approval was granted by the ethics committee of S. Maria Hospital, Terni, Italy. Informed consent was obtained from all participants. 


\section{Measures}

The following variables were assessed:

- Demographic variables. Age was measured in years, and gender was categorized as 1 for males and 2 for females.

- JDCS variables. These variables were measured with three scales of the Italian version of the Leiden Quality of Work Life Questionnaire for Nurses $(\mathrm{LQWQ}-\mathrm{N})^{27)}$. These scales provide an occupationspecific measurements corresponding closely to the original operationalization of the JDCS model. Responses are measured on a 4-point scale ranging from 1 (totally disagree) to 4 (totally agree). Job demands were measured with one scale (work and time pressure: 4 items; $\alpha=0.74$; e.g., "I must care for too many patients at once"). Job control (8 items; $\alpha=0.77$ ) was measured by combining skill discretion ( 4 items; e.g., "My work is varied") and decision authority (4 items; e.g., "I can decide for myself when to carry out patient-related tasks and when to carry out non-patient-related tasks") scales. In line with the recommendations of Karasek and Theorell ${ }^{3)}$, perceived emotional and practical social support was assessed by combining social support from supervisor (6 items; e.g., "I can count on the support of my direct supervisor when I face a problem at work") and social support from co-workers (6 items; e.g., "The nurses in my department work well together").

- Personal goal facilitation (PGFW). Personal goal facilitation through work was measured with an adapted version of the workplace questionnaire of the goal facilitation inventory ${ }^{28)}$.

Respondents answered the same question for each of 40 higher-order personal goals: "To what extent can you achieve the following goals through your work?" Answers could be provided on a 10-point scale (1=not at all; 10=completely). Some examples of higher order goals are as follows: "Performing well." and "Supporting others.". To examine the factorial structure of PGFW, we conducted exploratory factor analysis (EFA) as well as confirmatory factor analysis (CFA). EFA revealed the presence of one factor explaining $47.2 \%$ of the variance. An inspection of the scree plot revealed a clear break after the first component. This was further supported by the results of parallel analysis, which showed only one dimension with eigenvalues exceeding the corresponding criterion values for a randomly generated data matrix of the same size. CFA showed that one-factor model $\left(\chi^{2}=3014.15 ; \mathrm{df}=711 ; \mathrm{CFI}=0.90, \mathrm{RMSEA}=0.06\right.$ $(0.05-0.07))$ provided adequate fit to the data. Items were averaged to create the scale score (40 items; $\alpha=0.89$ ).

- Distress/well-being outcomes. Six distress/wellbeing outcomes were assessed: five job-related measures (job satisfaction, the three burnout components, and work engagement) and a general strain measure: somatic complaints. Job satisfaction was operationalized with the seven-item LQWQ-N scale (e.g., "I am satisfied with my job"). Burnout dimensions we assessed by the Italian version ${ }^{29}$ of the Maslach Burnout Inventory-Human Services Survey (MBI-HSS) ${ }^{20)}$ which contains the three subscales: emotional exhaustion (8 items; e.g., "I feel frustrated by my job"), depersonalization (5 items; e.g., "I don' $\mathrm{t}$ really care what happens to some patients"), and personal accomplishment (7 items; e.g., "I feel exhilarated after working closely with my patients"). In line with suggestions of Lee and Ashforth ${ }^{30)}$, we considered the three dimensions of the MBI-HSS. Participants were asked to rate from 0 (never) to 6 (daily) how often they experienced feelings described in each of the 20 items. Work engagement was measured with the shortened version of the Italian version ${ }^{31}$ of the Utrecht Work Engagement Scale (UWES-9) ${ }^{25}$. Each of the three dimensions (vigor, dedication, and absorption) was assessed with three items. Example items are: "During my work I feel full of energy" (vigor), "I am enthusiastic about my job" (dedication), and "When I am working very intensively, I feel happy" (absorption). Items for work engagement were rated on a seven-point scale ranging from 0 (never) to 6 (always). Given that the three dimensions of engagement are strongly intercorrelated when analyzed either at the level of the measuring scales ( $r$ usually higher than 0.65) or at the level of the latent factors ( $r$ usually higher than 0.80$)^{25)}$ and that our research is interested in work engagement as a global score, as recommended by Schaufeli and Bakker ${ }^{25}$, the scores for the three dimensions of work engagement were summed to form one overall score for work engagement.

Somatic complaints were assessed with the somatization subscale of the Italian version ${ }^{32}$ of the Symptoms Checklist ${ }^{33)}$. The 12 items of this subscale measured the degree to which subjects experienced physical states such as headaches and hot or cold spells during the last week. The answer categories ranged from 1 (not at all) to 5 (extremely).

\section{Data analysis}

Mediation analysis is most commonly conducted using causal steps ${ }^{34)}$. According to Baron and Kenny, four conditions are necessary to establish mediation: (a) the independent and mediating variables must be significantly related; (b) the independent and dependent variables must be significantly related; (c) the mediator and dependent variable must be significantly related, when controlling for the independent variable; and (d) the relationship between the independent variable and dependent variable should be nonsignifi- 
cant (full mediation) or weaker (partial mediation) when the mediator is added in regression analyses. Although it is the most common method, researchers have pointed out shortcomings of the Baron and Kenny approach and recommended reporting estimates of the size of the indirect effect and statistical significance tests ${ }^{35}$. We derived estimates of the indirect effects using a bootstrapping method. Bootstrapping is a nonparametric resampling procedure used to test mediation effects. Bootstrap sampling distributions rely on resampling the original dataset $K$ (usually $>1,000)$ number of times to achieve the direct and indirect effects. Several bootstrap confidence intervals can be used including percentile, bias corrected, and bias corrected accelerated. The latter two bootstrap confidence intervals are an improvement over the percentile method, because they can be used with smaller samples and have higher power for detecting mediation effects ${ }^{35)}$. Mediation exists if the value zero is not included in the confidence interval. In accordance with Preacher and Hayes ${ }^{35)}$, we estimated 5,000 bootstrap samples in which the independent variables were job demands, control, and social support, the mediator was personal goal facilitation through work, and the dependent variables were somatic complaints, emotional exhaustion, depersonalization, personal accomplishment, job satisfaction, and work engagement. We also included gender and age as covariates in the model, because these demographic variables may confound the results ${ }^{6}$. Moreover, we also included type of ward as a covariate, because preliminary analysis showed significant differences between ward types in the perception of social support $(\mathrm{F}=4.68$; $p<0.01)$, PGFW $(\mathrm{F}=3.70 ; p<0.05)$, and emotional exhaustion $(\mathrm{F}=4.19 ; p<0.01)$. Given that "type of ward" is a categorical variable, we adopted a dummy coding in the regression analyses. No significant differences in the predictors and dependent variables were identified for educational level, number of working hours, and type of shift work.

Recapitulating, to test hypothesis 1 (concerning the associations between the psychosocial job dimensions and PGFW), a hierarchical regression analysis was conducted. The first block included age and gender; in the second step, the psychosocial job variables were entered. To test hypothesis 2 (concerning the associations between PGFW and the outcomes of the study, above and beyond psychosocial job variables) and hypothesis 3 (stating that the association between psychosocial job variables and the outcomes would be mediated by PGFW), a second series of regression analyses was carried out. In the first block, we included age and gender, and in the second step, the JDCS variables were entered; finally, PGFW entered in the third step. The IBM SPSS Ver. 21 (SPSS Inc.,
Chicago, IL, USA) statistical analysis software was used. To test the mediation effect itself, we followed the logic outlined by Preacher and Hayes ${ }^{35}$. That is, rather than focusing on the strength of the association between the psychosocial job variables and the outcomes of the study as proposed by Baron and Kenny ${ }^{35)}$, we estimated the indirect effects using a bootstrapping method and adopting the script version of the indirect SPSS macro published by Preacher and Hayes $^{35)}$.

\section{Results}

Descriptive data and zero-order Pearson correlations of the study variables are displayed in Table 1. All scales measuring the study variables had acceptable levels of internal consistency (alpha coefficients ranged from 0.69 to 0.89 ). Furthermore, the correlations showed that the associations between PGFW on the one hand and psychosocial job variables and outcome variables on the other generally met our expectations. More specifically, PGFW was associated both with psychosocial job variables and all outcomes except depersonalization. High levels of personal goal facilitation through work were related to high levels of job control, social support, personal accomplishment, job satisfaction, and work engagement and to low values of job demands, emotional exhaustion, and somatic complaints.

\section{The mediation role of personal goal facilitation} through work.

The regression results for testing mediation are reported in Table 2. All psychosocial job variables were related to PGFW. Lower levels of job demands (beta $=-0.16 ; p<0.05$ ) and higher levels of both job control (beta $=0.25 ; p<0.001$ ) and social support (beta $=0.23 ; p<0.01$ ) were associated with higher scores for PGFW (hypothesis 1 was supported).

Concerning the effects of psychosocial job variables on somatic complaints, a close inspection of Table 2 indicated that, after controlling for gender, age, and type of ward, higher levels of job demands (beta $=0.21, p<0.01$ ) and lower levels of job control (beta $=-0.16, p<0.05$ ) were associated with higher levels of somatic complaints. Furthermore, we found that higher levels of PGFW were associated with lower levels of somatic complaints (accounting for $2 \%$ of the variance; beta $=-0.15 ; p<0.01)$ above and beyond the effects of job demands, control, and social support variables. Nurses with low scores for PGFW were more likely to experience high levels of somatic complaints (hypothesis 2 supported). As shown in the results for the bootstrap confidence intervals presented in Table 3, the relationship between job demands and somatic complaints was partially mediated by personal 


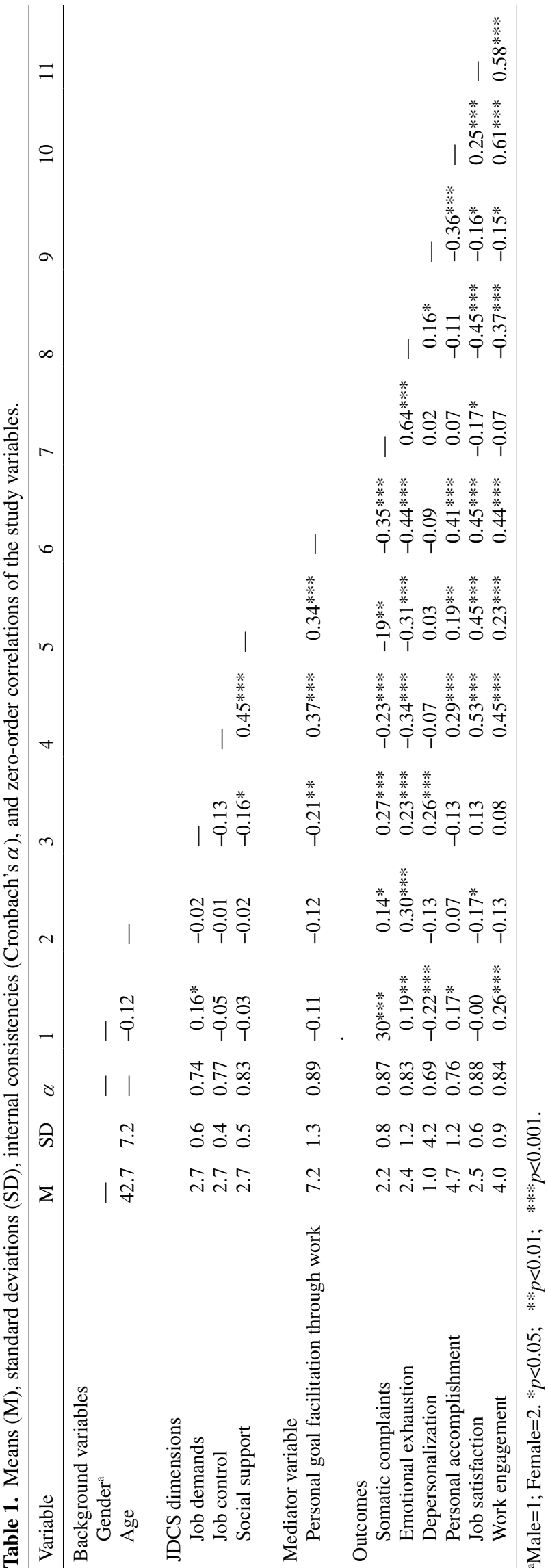

goal facilitation through work, and the relationship between job control and somatic complaints was fully mediated by personal goal facilitation through work. Furthermore, assessment of the indirect effect through bootstrapping showed that the mediating effect of PGFW for social support was significant (hypothesis 3 was supported).

Regarding emotional exhaustion, the results in Table 2 showed that after controlling for gender, age, and type of ward, nurses who reported higher levels of job demands (beta $=0.15, p<0.05$ ) and nurses who reported lower levels of job control (beta $=-0.24, p<0.001$ ) have higher levels of emotional exhaustion. These results showed that PGFW, after controlling for demographic variables and psychosocial job dimensions, was negatively related to emotional exhaustion (accounting for $5 \%$ of the variance; beta $=-0.25, p<0.001)$, supporting hypothesis 2 . The results of assessment of indirect effects through bootstrapping described in Table 3 showed that the mediating effect of PGFW for all psychosocial job variables was significant. Hypothesis 3 was also supported in this case.

With respect to depersonalization, the results in Table 2 indicated that it was only positively related to job demands (beta $=0.22 ; p<0.01$ ). PGFW was not associated with depersonalization (hypothesis 2 was not supported). As shown in Table 3, the mediation hypothesis of PGFW was not supported (hypothesis 3); PGFW did not mediate the associations between psychosocial job variables and depersonalization.

With regard to personal accomplishment, after controlling for gender, age, and type of ward, those who reported lower levels of job demands (beta $=-0.13$, $p<0.05$ ) and higher levels of job control (beta $=0.27$, $p<0.001$ ) had higher levels of personal accomplishment as shown in Table 2. The results showed that PGFW was positively related to personal accomplishment (accounting for $11 \%$ of the variance; beta $=0.38$, $p<0.001$ ), supporting hypothesis 2 . In addition, the results showed that, after PGFW was taken into account, the effect of job demands (beta $=-0.07, p>$ 0.05) was not significant, suggesting full mediation by PGFW, and the effect of job control (beta=0.17, $p<0.05)$ was weaker, albeit still significant, suggesting partial mediation. Furthermore, assessment of the indirect effect through bootstrapping described in Table 3 showed that the mediating effect of PGFW for demands, control, and social support was significant (hypothesis 3 was supported).

As shown in Table 2, after controlling for gender, age, and type of ward, high levels of both job control (beta $=0.39, p<0.001$ ) and social support (beta $=0.27$, $p<0.001)$ were associated with high levels of job satisfaction. The results demonstrated that nurses with high levels of PGFW (accounting for $4 \%$ of the vari- 
Table 2. Testing the mediation effect of personal goal facilitation through work (PGFW) in the relationship between psychosocial job characteristics and distress/well-being: R-squares and standardized estimates (betas) of the regression analyses

\begin{tabular}{|c|c|c|c|c|c|c|c|}
\hline \multirow[b]{2}{*}{ Predictors } & \multirow{2}{*}{$\begin{array}{c}\text { Mediator } \\
\text { PGFW }\end{array}$} & \multicolumn{6}{|c|}{ Outcomes } \\
\hline & & $\mathrm{SC}$ & EE & DP & PA & JS & ENG \\
\hline Gender $^{\mathrm{a}}$ & -0.07 & $0.29 * * *$ & $0.24 * * *$ & $-0.16^{*}$ & $0.19 * *$ & -0.04 & $0.25 * * *$ \\
\hline Age & -0.13 & $0.17 *$ & $0.27 * * *$ & $-0.14 *$ & 0.08 & $-0.18 * *$ & -0.10 \\
\hline Ward 1 & $-0.18^{*}$ & $0.14 *$ & $0.14 *$ & 0.06 & -0.11 & -0.01 & -0.09 \\
\hline Ward 2 & -0.11 & 0.10 & -0.08 & 0.00 & 0.00 & 0.09 & -0.00 \\
\hline$\Delta \mathrm{R}^{2}$ & $0.05^{*}$ & $0.13 * * *$ & $0.15^{* *}$ & 0.04 & $0.05^{*}$ & 0.04 & $0.08 * *$ \\
\hline Gender $^{\mathrm{a}}$ & -0.00 & $0.23 * * *$ & $0.19 * *$ & $-0.21 * *$ & $0.23 * * *$ & 0.01 & $0.27 * * *$ \\
\hline Age & -0.11 & $0.16 *$ & $0.26 * * *$ & $-0.14 *$ & 0.09 & $-0.16 * *$ & -0.10 \\
\hline Ward 1 & $-0.16^{*}$ & 0.12 & 0.12 & 0.04 & -0.09 & 0.00 & -0.08 \\
\hline Ward 2 & $-0.17^{*}$ & $0.14^{*}$ & -0.04 & -0.00 & -0.01 & 0.01 & -0.02 \\
\hline Demands & $-0.16^{*}$ & $0.21 * *$ & $0.15 *$ & $0.22 * *$ & $-0.13 *$ & -0.04 & 0.11 \\
\hline Control & $0.25 * * *$ & $-0.16^{*}$ & $-0.24 * * *$ & -0.07 & $0.27 * * *$ & $0.39 * * *$ & $0.45 * * *$ \\
\hline Social Support & $0.23 * * *$ & -0.10 & -0.12 & 0.07 & 0.03 & $0.27 * * *$ & 0.06 \\
\hline$\Delta \mathrm{R}^{2}$ & $0.20 * * *$ & $0.10 * * *$ & $0.13 * * *$ & $0.05 *$ & $0.10 * * *$ & $0.33 * * *$ & $0.22 * * *$ \\
\hline Gender $^{\mathrm{a}}$ & - & $0.23 * * *$ & $0.19 * *$ & $-0.21 * *$ & $0.24 * * *$ & 0.02 & $0.27 * * *$ \\
\hline Age & - & $0.14 *$ & $0.23 * * *$ & $-0.15^{*}$ & $0.14 *$ & $-0.14 *$ & -0.06 \\
\hline Ward 1 & - & 0.10 & 0.08 & 0.01 & -0.02 & 0.04 & -0.02 \\
\hline Ward 2 & - & 0.11 & -0.08 & -0.03 & 0.05 & 0.05 & 0.04 \\
\hline Demands & - & $0.19 * *$ & $0.13^{*}$ & $0.20 * *$ & -0.07 & -0.00 & 0.11 \\
\hline Control & - & -0.10 & $-0.18 *$ & -0.04 & $0.17 *$ & $0.33 * * *$ & $0.36 * * *$ \\
\hline Social Support & - & -0.07 & -0.07 & 0.10 & -0.05 & $0.24 * * *$ & -0.01 \\
\hline PGFW & - & $-0.15^{* *}$ & $-0.25 * * *$ & -0.13 & $0.38 * * *$ & $0.23 * * *$ & $0.36^{* * *}$ \\
\hline$\Delta \mathrm{R}^{2}$ & - & $0.02 *$ & $0.05^{* * *}$ & 0.01 & $0.11 * * *$ & $0.04 * * *$ & $0.10 * * *$ \\
\hline $\mathrm{R}^{2}$ & 0.25 & 0.24 & 0.33 & 0.11 & 0.26 & 0.41 & 0.40 \\
\hline Adj $R^{2}$ & 0.23 & 0.21 & 0.30 & 0.07 & 0.23 & 0.38 & 0.38 \\
\hline
\end{tabular}

${ }^{a}$ Male $=1$; Female $=2 . * p<0.05$; $* * p<0.01$; *** $p<0.001$. Ward 1, surgical ward vs. emergency ward; ward 2, medical ward vs. emergency ward; PGFW, personal goal facilitation through work, SC, somatic complaints; EE, emotional exhaustion; DP, depersonalization; PA, personal accomplishment; JS, job satisfaction; ENG, engagement.

ance; beta $=0.23 ; p<0.001)$ were more satisfied with their jobs than their counterparts with lower levels of PGFW (hypothesis 2 was supported). Further, the results also showed that, after PGFW was taken into account, both the effects of job control (beta $=0.33$, $p<0.001$ ) and social support (beta $=0.24, p<0.001$ ) were weaker, albeit still significant, which suggests partial mediation. Again, as shown in Table 3 all indirect effects were significantly different from zero. Thus, the relationships between psychosocial job dimensions on the one hand and job satisfaction on the other were partially mediated by PGFW (hypothesis 3 was also supported in this case).

Finally, with regard to work engagement, the results depicted in Table 2 showed that job control (beta $=0.45$, $p<0.001)$ was positively associated with work engagement and that this association was weaker, although still significant, after inclusion of the significant effect of PGFW (accounting for 10\% of the variance; beta $=0.36, p<0.001$ ) (hypothesis 2 supported). As shown in Table 3, all indirect effects were significantly different from zero. Thus, the relationships between all JDCS variables and work engagement were mediated by PGFW (hypothesis 3 supported).

\section{Discussion}

The present study was designed to investigate the mediating role of personal goal facilitation through work in the relationship between psychosocial job variables and distress/well-being outcomes. The results were supportive for most of the hypotheses.

First, hypothesis 1 was supported. Favorable psychosocial job conditions (low demands, high control, and high social support) are associated with high scores for the perceptions of employees regarding pursuit and attainment of their personal goals through 
Table 3. Bootstrap confidence intervals for the mediation effect of personal goal facilitation through work in the relationship between job characteristics and distress/well-being outcomes

\begin{tabular}{|c|c|c|c|c|c|}
\hline & \multicolumn{2}{|c|}{ Corrected 95\% CI } & \multicolumn{2}{|c|}{ Accelerated 95\% CI } & \multirow[b]{2}{*}{$p$ value } \\
\hline & Lower & Upper & Lower & Upper & \\
\hline \multicolumn{6}{|c|}{ Somatic complaints } \\
\hline Demands & 0.015 & 0.144 & 0.013 & 0.133 & $<0.05$ \\
\hline Control & -0.315 & -0.029 & -0.305 & -0.029 & $<0.01$ \\
\hline Social support & -0.265 & -0.032 & -0.261 & -0.032 & $<0.01$ \\
\hline \multicolumn{6}{|c|}{ Emotional exhaustion } \\
\hline Demands & 0.041 & 0.215 & 0.030 & 0.191 & $<0.05$ \\
\hline Control & -0.385 & -0.082 & -0.384 & -0.082 & $<0.001$ \\
\hline Social support & -0.358 & -0.088 & -0.354 & -0.085 & $<0.005$ \\
\hline \multicolumn{6}{|l|}{ Depersonalization } \\
\hline Demands & -0.004 & 0.044 & -0.008 & 0.073 & ns \\
\hline Control & -0.072 & 0.009 & -0.150 & 0.029 & ns \\
\hline Social support & -0.060 & 0.007 & -0.127 & 0.019 & ns \\
\hline \multicolumn{6}{|c|}{ Personal accomplishment } \\
\hline Demands & -0.180 & -0.045 & -0.173 & -0.037 & $<0.05$ \\
\hline Control & 0.133 & 0.383 & 0.114 & 0.355 & $<0.001$ \\
\hline Social support & 0.121 & 0.340 & 0.112 & 0.321 & $<0.005$ \\
\hline \multicolumn{6}{|l|}{ Job satisfaction } \\
\hline Demands & -0.193 & -0.027 & -0.191 & -0.027 & $<0.05$ \\
\hline Control & 0.062 & 0.269 & 0.064 & 0.273 & $<0.001$ \\
\hline Social support & 0.072 & 0.255 & 0.066 & 0.242 & $<0.005$ \\
\hline \multicolumn{6}{|l|}{ Work engagement } \\
\hline Demands & -0.282 & -0.069 & -0.260 & -0.054 & $<0.05$ \\
\hline Control & 0.129 & 0.409 & 0.114 & 0.387 & $<0.001$ \\
\hline Social support & 0.151 & 0.435 & 0.130 & 0.412 & $<0.005$ \\
\hline
\end{tabular}

Gender, age and type of ward were controlled for in the analyses. Confidence intervals (CIs) were set to $95 \%$. An indirect effect exists if the value zero is not included in the confidence interval.

work. Clearly these findings reaffirm the importance of psychosocial job conditions for employee wellbeing also in terms of the opportunities available to attain their personal goals ${ }^{7}$.

The second hypothesis deals with the direct relationship between personal goal facilitation through work and outcomes. Our results largely supported this hypothesis. In our regression analyses, personal goal facilitation through work explained significant additional variance (from 2 to $11 \%$ ) in psychological distress (somatic complaints and emotional exhaustion) and job-related well-being (personal accomplishment, job satisfaction, and work engagement) after controlling for demographic indicators and psychosocial job variables. These results are in line with previous findings by ter Doest and colleagues ${ }^{12)}$, who found that personal goal facilitation through work accounted for substantial variance in psychological distress/ well-being outcomes (somatic complaints, emotional exhaustion, personal accomplishment, and job satisfaction), even after taking into account the role of psychosocial job dimensions from the JDCS model. In line with the general literature on self-regulation, progressing towards or attaining valued personal goals is an autonomous determinant of psychological distress and well-being ${ }^{36}$. Goal attainment elicits positive states, whereas people who fail to live up to self-imposed goal standards or those imposed by others experience a range of negative emotions ${ }^{15}$.

Contrary to our expectations, depersonalization was not associated with personal goal facilitation through work. This is probably because depersonalization refers specifically to relationships with patients as opposed to the other outcomes of the study. Depersonalization represents indifference or a "distant attitude" toward patients and work in general "in that it reduces the energy available for performing work and for developing creative solutions to the problems 
work presents" ${ }^{37)}$. Thus depersonalization represents a sort of cognitive, emotional and behavioral "disinvestment" in work life. Therefore, it could be difficult to find relationships with self-regulatory constructs at work, such as personal goal facilitation through work.

A close examination of the direct effects of psychosocial job variables on outcomes reveals that job demands, above and beyond the effects of the demographic variables and the mediator, were directly related to all distress outcomes (somatic complaints, emotional exhaustion, and depersonalization). However, job demands did not show any significant direct association with job-related well-being outcomes (personal accomplishment, job satisfaction, and work engagement). These results are in line with previous studies ${ }^{6}$ ) and suggest that job demands (especially time pressure) are primarily related to psychological distress variables providing support for the health impairment process. This is basically an energetic process of wearing out in which high job demands exhaust the employee's energy backup. The long-term consequences of this process will be high psychophysiological strain, which in turn will exert a negative impact on health ${ }^{3}$. Job control was directly and negatively related to emotional exhaustion and showed direct positive associations with all job-related well-being dimensions (personal accomplishment, job satisfaction, and work engagement). Social support showed a direct positive association with job satisfaction. These results are consistent with an autonomous motivational process of job resources ${ }^{6}$. This motivational process is triggered by the perception of availability of job resources (in our case, specifically job control) that are instrumental to the pursuit of work goals and foster employees' growth, learning, and development ${ }^{38)}$. Therefore, job resources are not only necessary to deal with job demands but are also important in their own right.

With regard to the indirect association between psychosocial job variables and outcomes via PGFW, our results showed that all bootstrapping tests of indirect effects were significant, except for depersonalization. In addition, the associations between job demands and control on the one hand, and personal accomplishment on the other hand were fully mediated by personal goal facilitation through work. Thus hypothesis 3 was largely supported, psychosocial job characteristics can influence employees psychological well-being directly and indirectly through personal goal facilitation. Favorable psychosocial job conditions (low demands, high control, and high social support) may influence the extent to which one's job facilitates the attainment of one's personal goals, which in turn may influence psychological well-being. Conversely, unfavorable psychosocial job condi- tions (high workload, lack of control, and low social support) may hinder the attainment and pursuit of personal goals, which, in turn, is likely to negatively influence employee well-being.

A few limitations of the present study should be mentioned. First and foremost, the study was conducted with a cross-sectional design. This does not permit conclusions regarding the causality of the relationships between psychosocial job dimensions, personal goal facilitation through work, and psychological distress/well-being. These relationships could be reciprocal (e.g., low personal goal facilitation through work can lead to higher levels of psychological distress, and vice versa). Prospective studies should be conducted to evaluate the exact nature of these relationships.

The second limitation of the present research is that only nurses, all working for the same organization, were involved, and the large majority of them were female. This may limit the generalizability of the findings. Thus, the specific nature of the present sample underlines the need to replicate the current study in other samples.

Finally, the assessment of job demands focused mainly on work and time pressure. Although this is in line with the operationalization of the construct of demands in the JDCS model ${ }^{3)}$, it would be recommendable for future studies to include other demanding aspects of jobs. Recently, a distinction has been made between "challenge" demands and "hindrance" demands ${ }^{39)}$. Time pressure, job complexity, job responsibility, pressure to complete tasks, and concentration demands, which belong to the overtaxing regulation category, are challenge demands, whereas job hindrance demands included measures of situational constraints, such as uncertainty, role ambiguity, and role conflict.

The practical implications of this study relate to the relations between JDCS variables and personal goal facilitation through work. Favorable psychosocial job characteristics appear to be instrumental in the goal pursuit process and, consequently, in occupational and general well-being. Therefore, it is advisable to focus interventions on reduction of excessive job demands and on the improvement of job resources. Specific interventions could incorporate the following: taking measures to avoid structural and incidental understaffing, implementation of autonomous teams to enhance job control, and training regarding leadership qualities for supervisors ${ }^{40)}$. Our findings also suggest that organizations interested in employees' well-being should take employees' perceptions of personal goal facilitation through work into account. This could be done by screening work populations for impairment of the attainment of personal goals at work. 
Acknowledgments: We gratefully acknowledge the cooperation of the nurses who participated in this study.

Source of financial support: This research received no specific grant from any funding agency in the public, commercial, or not-for-profit sectors.

\section{References}

1) Pisanti $R$, van der Doef $M$, Maes S, Lazzari $D$, Bertini M. Job characteristics, organizational conditions, and distress/well-being among Italian and Dutch nurses: a cross-national comparison. Int $\mathrm{J}$ Nurs Stud 2011; 48: 829-37.

2) Chaloff J. Mismatches in the Formal Sector, Expansion of the Informal Sector: Immigration of Health Professionals to Italy. OECD Health Working Papers, 34. Paris: OECD Publishing; 2008.

3) Karasek R, Theorell T. Healthy work: Stress, productivity, and the reconstruction of working life. New York: Basic Books; 1990.

4) Kompier M, Taris T. Psychosocial risk factors and work-related stress: State of the art and issues for future research. In: Antoniou A, Cooper C, editors. Research companion to Organizational Health Psychology. Cheltenham: Edward Elgar Publishing LTD; 2005. p. 59-69.

5) de Jonge J, Dormann C. The DISC Model: Demand-Induced Strain Compensation Mechanisms in Job Stress. In: Dollard MF, Winefield AH, Winefield HR, editors. Occupational Stress in the Service Professions. London: Taylor \& Francis; 2003. p. 43-74.

6) Bakker $\mathrm{AB}$, Demerouti $\mathrm{E}$, Verbeke W. Using the job demands-resources model to predict burnout and performance. Hum Resour Manage 2004; 43: 83-104.

7) Pomaki G, Maes S. Predicting quality of work life: from work conditions to self-regulation. In Gullone E, Cummins RA, editors. Social Indicators Research Book Series: The universality of subjective well-being indicators. A multi-disciplinary and multi-national perspective. Vol. 16. Dordrecht (the Netherlands): Kluwer Academic; 2002. p. 151-73.

8) Ryan RM, Deci EL. Self-determination theory and the facilitation of intrinsic motivation, social development, and well-being. Am Psychol 2000; 55: 68-78.

9) Gagné M, Deci EL. Self-determination theory and work motivation. J Organ Behav 2005; 26: 331-62.

10) Demerouti E, Bakker A, Nachreiner F, Schaufeli W. The job demands-resources model of burnout. J Appl Psychol 2001; 86: 499-512.

11) Hyvonen K, Feldt T, Tolvanen A, Kinnunen U. The role of goal pursuit in the interaction between psychosocial work environment and occupational well-being. J Vocat Behav 2010; 76: 406-18.

12) ter Doest L, Maes S, Gebhardt WA, Koelewijn H. Personal goal facilitation through work: implica- tions for employee satisfaction and wellbeing. Appl Psychol Int Rev 2006; 55: 192-219.

13) Austin JT, Vancouver JB. Goal constructs in psychology: structure, process, and content. Psychol Bull 1996; 120: 338-75.

14) Adriaenssens J, Gucht V, Maes S. Association of goal orientation with work engagement and burnout in emergency nurses. J Occup Health 2015 (doi: 10.1539/joh.14-0069-OA).

15) Koestner R, Lekes N, Powers TA, Chicoine E. Attaining personal goals: self-concordance plus implementation intentions equals success. J Pers Soc Psychol 2002; 83: 231-44.

16) Maier G, Brunstein J. The role of personal work goals in newcomers' job satisfaction and organizational commitment: a longitudinal analysis. J Appl Psychol 2001; 86: 1034-42.

17) Muller L, Spitz E. Effects of personal goal disturbance on psychological distress. Rev Eur Psychol Appl 2010; 60: 105-12.

18) Van Horn JE, Taris TW, Schaufeli WB, Schreurs PJG. The structure of occupational well-being: a study among Dutch teachers. J Occup Organ Psychol 2004; 77: 365-75.

19) Dollard MF, LaMontagne AD, Caulfield N, Blewett $\mathrm{V}$, Shaw A. Job stress in the Australian and international health and community services sector: a review of the literature. Int J Stress Manag 2007; 14: 417-45.

20) Maslach C, Jackson S, Leiter MP. Maslach Burnout Inventory Manual. 3rd ed. Palo Alto (CA): Consulting Psychologists Press; 1996. (All versions of the MBI are now published online by Mind Garden at: mindgarden.com).

21) Estryn-Béhar M, Kaminski M, Peigne E, et al. Stress at work and mental health status among female hospital workers. Br J Ind Med 1990; 47: 20-8.

22) Weiss HM. Deconstructing job satisfaction: separating evaluations, beliefs and affective experiences. Hum Resource Manag Rev 2002; 22: 173-94.

23) Lu H. While A. Barriball L. Job satisfaction among nurses: a literature review. Int J Nurs Stud 2005; 42: 211-27.

24) Laschinger HKS, Leiter MP. The impact of nursing work environments on patient safety outcomes: the mediating role of burnout engagement. J Nurs Adm 2006; 36: 259-67.

25) Schaufeli W, Bakker A. UWES-Utrecht Work Engagement Scale. Utrecht (The Netherlands): Occupational Health Psychology Unit, Utrecht University; 2004.

26) Field AP. Discovering statistics using SPSS: and sex and drugs and rock ' $n$ ' roll (4th edition). London: Sage. 2013.

27) Pisanti $R$, van der Doef $M$, Maes S, Lazzari D, Violani C. Psychometric properties of the Italian version of Leiden Quality of Work Questionnaire for Nurses (LQoWQ-N). Psychol Health 2009; 24(SI): 318. 
28) Maes S, ter Doest L, Gebhardt W. The goal facilitation inventory - workplace version: factor structure and psychometric properties. Leiden (The Netherlands): Health Psychology, Leiden University; 2005.

29) Pisanti R, Lombardo C, Lucidi F, Violani C, Lazzari D. Psychometric properties of the Maslach Burnout Inventory for Human Services among Italian nurses: a test of alternative models. J Adv Nurs 2013; 69: 697-707.

30) Lee RT, Ashforth BE. On the meaning of Maslach's three dimensions of burnout. J Appl Psychol 1990; 75: 743-7.

31) Pisanti R, Paplomatas A, Bertini M. Misurare le dimensioni positive nel lavoro in sanità : un contributo all'adattamento italiano della UWES Utrecht Work Engagement Scale. [Measuring the positive dimensions among health care workers: a contribution to the Italian Validation of the UWESUtrecht Work Engagement Scale]. G Ital Med Lav Erg. 2008; 30 (Suppl. A Psicologia): A111-9.

32) Violani C, Catani L. Un contributo alla validazione italiana dell'SCL-90 - R. [A contribute to the Italian validation of the Scl-90 Revised version]. Proceedings of the I Italian Congress of Health Psychology, Orvieto (Italy); 1995.

33) Derogatis LR. SCL-90-R: Administration, scoring $\&$ procedures manual II. 2nd edition. Baltimore:
Clinical Psychometric Research; 1983.

34) Baron RM, Kenny DA. The moderator-mediator variable distinction in social psychology research: conceptual, strategic and statistical considerations. J Pers Soc Psychol 1986; 51: 1173-82.

35) Preacher KJ, Hayes AF. Asymptotic and resampling strategies for assessing and comparing indirect effects in multiple mediator models. Behav Res Methods 2008; 40: 879-91.

36) Elliot AJ, Sheldon KM. Avoidance personal goals and the personality-illness relationship. J Pers Soc Psychol 1998; 75: 1282-99.

37) Leiter MP, Schaufeli WB. Consistency of the burnout construct across occupations. Anxiety Stress Coping 1996; 9: 229-43.

38) Crawford ER, Lepine JA, Rich BL. Linking job demands and resources to employee engagement and burnout: a theoretical extension and meta-analytic test. J Appl Psychol 2010; 95: 834-48.

39) Podsakoff NP, LePine JA, LePine MA. Differential challenge stressor-hindrance stressor relationships with job attitudes, turnover intentions, turnover, and withdrawal behavior: a meta-analysis. J Appl Psychol 2007; 92: 438-54.

40) Tayfur O, Arslan M. The role of lack of reciprocity, supervisory support, workload, and work-family conflict on exhaustion: evidence from physicians. Psychol Health Med 2013; 18: 564-75. 